\title{
Prevalence and Associated Risk Factors of Eimeria Infections in Dairy Calves in Haramaya University, Haramaya and Harar Towns
}

\author{
Nagaro Damana ${ }^{2}$, Walkite Furgasa ${ }^{2 *}$ and Birhanu Sibhat ${ }^{1}$ \\ ${ }^{1}$ College of veterinary medicine, Haramaya University, P.O.Box 137, Diredawa, Ethiopia \\ ${ }^{2}$ School of Veterinary Medicine, Wollega University, P.O.Box 395, Nekemte, Ethiopia
}

Received: 14 November, 2017; Accepted: 9 March, 2018; Published: 12 March, 2018

*Corresponding author: Walkite Furgasa, School of Veterinary Medicine, Wollega University, P.O.Box 395, Nekemte, Ethiopia. Tel: +251921165829.Email: walkiteharamaya@gmail.com

\begin{abstract}
A cross sectional study was conducted from November 2014 up to March 2015 in Haramaya University, Haramaya and Harar towns to determine the prevalence of Eimera infection in calves. Fecal samples were collected from a total of 266 calves between the ages of 1 day to 6 month. Samples were examined for the presence of Eimeria oocyst by flotation techniques. Out of 266 calves, 65(24.4\%) were found to be positive for Eimeria infection. There were statistically significant differences $(\rho<0.05)$ in the prevalence of Eimeria between calves with different fecal consistency, hygienic status of the farm and calf housing. Diarrheic calves had significantly higher prevalence than calves with soft and normal feces. Poor hygienic status in the farm increased the prevalence of Eimeria infection and calves kept mixed with other animals of the herd had higher prevalence $(35.33 \%)$ of Eimeria infection than calves separately housed $(13.53 \%)$ with their peers. No statistically significant prevalence difference $(P>0.05)$ was observed between calves of different sex, age and farm size. In conclusion, the study revealed that calf eimeiosisis was prevalent in Haramaya University, Haramaya and Harar towns Dairy farms and consequently affects the productivity of the sector. Hence, appropriate disease prevention and control measures are require to be undertaken to reduce its effect.
\end{abstract}

Key words: Calves; Coccidiosis; Eimeria; Associated risk factor; Haramaya; Harar town

\section{Introduction}

Eimeria infections are one of the most common and important disease of cattle worldwide. Bovine coccidiosis has been observed in almost all areas where cattle are raised and is usually most common and important in calves younger than 1 year. All calves managed under conventional systems are exposed and become infected early in life. At least 13 different coccidial species are known to infect cattle, but not all are pathogenic. The two most pathogenic species are E. bovis and E. zurnii [1].

Many studies indicated that under natural conditions, mixed species infections are much more common than mono-species infections [2]. Eimeriosis in cattle is particularly a problem of confined animals kept under intensive husbandry practices. The disease is more common in housed animals than in those on pastures. In associations with other enter pathogens, coccidia have been indicated as an important cause of diarrhea in calves [3].

All age groups of cattle are susceptible to infection, but clinical eimeriosis is most common in young animals. Coccidiosis in cattle commonly occurs as subclinical disease without signs of the disease and involving great economic losses due to reduced appetite, reduced body weight, impaired feed conversion, unthriftness, diarrhea, dysentery, anemia, and increased susceptibility to other diseases [4].

The development of clinical coccidiosis in cattle mainly depends on factors like species of Eimeria, age of infected animal, number of oocysts ingested, presence of concurrent infections, and type of production system and management practices [5]. Compared to clinical coccidiosis, subclinical coccidiosis is economically more important and may account for over $95 \%$ of all the losses associated with coccidiosis and can cost cattle ranchers more than US $\$ 400$ million per annum. It can also delay growth of calves by as much as 2 months [6]. A number of epidemiological factors like moisture, temperature, and oxygen tension influence the pattern of the disease [7]. In addition, stress factors like weaning, change of diet, harsh environment, poor nutrition and sanitation, and overcrowding can increase level of infection and incidence of the disease due to stress-induced immune suppression [8]. Thus determination of prevalence, species composition, associated risk factors, and animal management and husbandry practices is very useful in designing efficient control strategies [9].

The prevalence, species composition, and importance of bovine coccidiosis have been documented in various countries of the world; however, there is scarcity of reports on animal morbidity and mortality in Ethiopia. Particularly in Eastern Hararghe, a single study available on the coccidia of cattle, reported an outbreak of coccidiosis due to Eimeria species with an overall prevalence of $22.7 \%$ in dairy farms in Dire Dawa [10]. As a result, there is paucity of information on the occurrence and 
losses associated with bovine Eimeria infection and very little attention has been given to the role of coccidiosis as the cause of disease and production losses in cattle in Eastern Haraghe Zone. Moreover, no attempt was made to determine the prevalence, and associated risk factors of Eimeria infections in cattle.

Therefore, the current study was designed:

- To estimate the prevalence of Eimeria infection in dairy calves in Haramaya University, Haramaya and Harar towns

- To identify and give recommendations on potential risk factors of Eimeria infections.

\section{Materials and Methods}

\section{Study Area Description}

The study was conducted in dairy farms in Haramaya University, Haramaya and Harar towns which are found in Eastern Hararghe Zone, Eastern Ethiopia. These sites are approximately $511 \mathrm{~km}, 506 \mathrm{~km}, 523 \mathrm{~km}$ East of Addis Ababa respectively. The elevation of the first two farm is about $2000 \mathrm{~m}$ above sea level and geographically located at $09^{\circ} 10^{\prime} 24^{\prime \prime} \mathrm{N}$ and $41^{\circ} 59^{\prime} 58^{\prime \prime} \mathrm{E}$ (HADB, 2009), whereas Harar dairy farm is located at $09^{\circ} 11^{\prime} 49^{\prime \prime}$ $\mathrm{N}$ longitudes and $42^{\circ} 03^{\prime} 03^{\prime \prime} \mathrm{E}$ longitude (HAOR, 2002). Haramaya University receives an average rainfall of approximately $900 \mathrm{~mm}$ and agro-climatically found at highland areas [11]. Harar receives annual rain fall ranges between $275-1000 \mathrm{~mm}$, and climatically found at midland (woynadega).

\section{Study Animal}

The study animals were calves between the ages of 1 day to 6 month old. A total of 266 fecal samples were collected and examined for Eimeria infection from different dairy farms in Haramaya University, Haramaya and Harar towns. Examined animals were categorized into two age groups as group I= 1day to 3 months age and group $\mathrm{II}=3$ to 6 months age which was determined by asking the owner of the animal orally [12].

\section{Study Design}

A Cross-sectional study was conducted from November 2014 to March 2015 to determine the Prevalence and risk factors of Eimeria infections in dairy calves in Haramaya University, Haramaya and Harar towns.

\section{Sample Size Determination}

The sample size required for this study was calculated based on sample size determination method for simple random sampling of infinite population [13] as follows:

$$
\mathrm{n}=\frac{1.96^{2}\left(\mathrm{p}_{\text {exp }}\left(1-\mathrm{p}_{\exp }\right)\right)}{\mathrm{d}^{2}}
$$

Where $\mathrm{n}=$ required sample size:

$$
\begin{aligned}
P_{\text {exp }} & =\text { expected prevalence } \\
d & =\text { desires absolute precision }
\end{aligned}
$$

Previous study undertaken in Dire Dawa in similar region to the current study reported prevalence of $22.7 \%$, [10].Therefore, this was taken as a basis for calculation of sample size. Accordingly, with $5 \%$ absolute precision at $95 \%$ confidence level, the number of calves required to determine the prevalence was found to be 266. Then, simple random sampling method was used to select the calves from dairy farms.

\section{Study Methodology}

About 10-20 g fresh faecal sample was collected per rectum from each calf using sterile disposable plastic gloves. Each sample was placed in a clean plastic container labelled and transported to Veterinary parasitology laboratory, College of Veterinary Medicine, Haramaya University on the same day of collection, and preserved at refrigeration temperature until processing within 24 hours of arrival. At the time of sampling, the name of the farm, date of sampling, consistency of the feces (soft, watery, or normal), age, sex, breed, calf housing, and hygienic status of farm and tag number was recorded for each calf on a recording format.

A $3 g$ portion of each of the 266 fecal samples collected was weighed out using a balance and put in a mortar. After grinding with pistil $40 \mathrm{ml}$ of sugar solution (specific gravity 1.27) was added, mixed thoroughly and poured into a $100-\mathrm{ml}$ glass beaker through a strainer. Then it was rinsed and the solution was poured into 15-ml centrifuge tubes but not filled. After centrifugation at $1,500 \mathrm{rpm}$ for $5 \mathrm{~min}$, more sugar solution was added until a convex meniscus was formed on top of the tube. A glass cover slip was placed on top of each tube and was left for $30 \mathrm{~min}$. Then, each glass cover slip was briskly lifted up and placed on a clean glass slide, not allowing formation of air bubbles. The entire area under each cover slip was examined under a binocular microscope at $40 \times$ magnification [14].

\section{Data Analysis}

Data collected from study sites were entered and stored in a Microsoft excel spread sheet program and coded for analysis. Statistical analysis was done on STATA 11.0 version statistical software. The prevalence was calculated for all data as the number of infected individuals divided by the number of sampled individual and multiplied by 100 For the purpose of this study, animal attributes such as age, sex, consistency of feces, hygiene, farm size, and calf housing were considered as risk factors [13]. Categorical data were analyzed first with the chi square $\left(\mathrm{x}^{2}\right)$ test for independence as a screening process. A P-value $<0.05$ was considered as statistically significant.

\section{Result}

\section{Overall Prevalence of Eimeria Infection in Calves}

Out of 266 fecal samples examined, 65 were positive for Eimeria oocysts and hence the overall prevalence was found to be $24.4 \%$. Accordingly, the prevalence of Eimeria infection relating to hygiene, consistency and calf housing were found to be significantly different $(\mathrm{p}<0.05)$ other factors such as age, sex and farm size were not significantly different (Table 1) 
Prevalence and Associated Risk Factors of Eimeria Infections in Dairy Calves in Haramaya University, Haramaya and Harar Towns

\begin{tabular}{|c|c|c|c|c|c|c|}
\hline \multicolumn{2}{|c|}{ Risk factors } & \multirow{2}{*}{$\begin{array}{c}\text { No. observed } \\
78\end{array}$} & \multirow{2}{*}{$\begin{array}{c}\text { No. Positive (\%) } \\
33(42.3 \%)\end{array}$} & \multirow{2}{*}{$\begin{array}{c}95 \% \mathrm{CI} \\
31.2-54.0\end{array}$} & \multirow{2}{*}{$\begin{array}{c}\mathrm{X}^{2} \\
19.109\end{array}$} & \multirow{2}{*}{$\begin{array}{c}\text { P-value } \\
0\end{array}$} \\
\hline Consistency & diarrhic & & & & & \\
\hline & normal & 127 & $22(17.32 \%)$ & $11.8-25.0$ & & \\
\hline & soft & 61 & $10(16.39 \%)$ & $8.2-28.1$ & & \\
\hline \multirow[t]{2}{*}{ Age } & $\leq 3$ month & 149 & $32(21.48 \%)$ & $15.8-28.9$ & 1.6069 & 0.205 \\
\hline & $>3$ month & 117 & $33(28.2 \%)$ & $2 \mathrm{~s} 0.3-37.3$ & & \\
\hline \multirow[t]{2}{*}{ Sex } & Female & 153 & $42(27.45 \%)$ & $20.6-35.2$ & 1.7729 & 0.183 \\
\hline & Male & 113 & $23(20.35 \%)$ & $13.7-29.0$ & & \\
\hline \multirow[t]{2}{*}{ Hygiene } & Poor & 117 & $41(35.04 \%)$ & $26.5-44.4$ & 12.726 & 0 \\
\hline & Good & 149 & $24(16.10 \%)$ & $10.6-23.0$ & & \\
\hline \multirow[t]{3}{*}{ Farm size } & Large & 118 & $27(22.9 \%)$ & $15.7-31.5$ & 0.2805 & 0.869 \\
\hline & Medium & 94 & $24(25.53 \%)$ & $17.1-35.6$ & & \\
\hline & Small & 54 & $14(25.9 \%)$ & $15.0-39.7$ & & \\
\hline \multirow[t]{2}{*}{ Calf housing } & Separated & 133 & $47(13.53 \%)$ & $8.22-20.54$ & 17.1225 & 0 \\
\hline & Mixed & 133 & 18(35.33\%) & $27.3-44.1$ & & \\
\hline
\end{tabular}

\section{Discussion}

The overall prevalence of Eimeria in calves recorded in this study (24.4\%) was lower than previous reported in Addis Ababa and Debre Zeit by which was $68.1 \%$ [12]. Also the prevalence of the present study was lower than previously reported in other countries by in turkey; in Canada; and in Mexico, who reported 68 $\%, 64.2 \%$ and $87.8 \%$ respectively $[15,16,17]$. However, the result of the present study was in agreement with the previous studies conducted in Ethiopia by in Bahir Dar; in Debre Zeit; Dawid et al. (2012) in Dire Dawa and in Kombolcha who reported 24.9 \%, 20 $\%, 22.7 \%$, and $31.9 \%$ respectively $[10,18,19,20]$. Also it was in agreement with report in other country by in Egypt which was $24.2 \%$ [21].

The lower prevalence of coccidiosis recorded in this study as compared to the areas with the higher prevalence could be due to the differences in agro-ecology, management types and husbandry practices of the study animals in different countries. Moreover this could also be due to the fact that the study has been undertaken mainly in dry season; hence, higher prevalence would have been recorded if the study was carried out in the rainy season. Warm moist conditions favors fast development of oocysts, which means that irrespective of season in different parts of the year maximum transmission, will occur under these conditions.

Analysis of risk factor in the association of disease occurrence has revealed that there was no statistically significant difference $(P>0.05)$ in prevalence between sex and Eimeria infection. These indicate that the sex does not have influence on the occurrence of Eimeria infection. This is due to either equal chance of accessing the oocysts or no difference on protective immunity for the disease.

There was no significant difference $(P>0.05)$ between the age of the calves with the risk of infection. However, the prevalence was somewhat higher in calves $3-6$ month age than $\leq 3$ month old. This is in line with the study by who reported that risk of infection by Eimeria species appeared to increase with the age of the examined calves [12]. This is true only for young calves, because Eimeria infection is most common in young cattle [3].

There was a statistically significant difference $(p<0.05)$ in prevalence of Eimeria infection between farms with different hygienic status. Consequently, calves belonging to the farms with poor hygiene showed significantly higher prevalence than calves belonging to the farms with relatively better hygiene. This could imply that poor sanitation in the calving and calf housing areas as well as poor management of housing favors infection with Eimeriosis. Obviously, poor ventilation, draughts, poor calf nutrition, heavy stocking, soiled bedding were regarded as risk factors for Eimeriosis [22].

There was statistically significant $(\mathrm{P}<0.005)$ difference in prevalence between fecal consistency with Eimeria infection which agrees with the finding of [23]. However, this finding disagrees with the report of [12]. In the present study, $42.3 \%$ (33/78) of diarrheic calves were found to be positive for Eimeria. However, there were no apparent clinical signs in most of the animals sampled for the study.

Absence of statistically significant difference between the herd sizes of the study animals might suggest equal likelihood of being infected with coccidiosis. However in this study the prevalence was bit higher in small herd size than large and medium herd size. This could be due to difference in calf housing, where most calves in small herd size were kept together and in large and medium herd size most of calves were kept separately, that observed during study period. This statement was in contradiction to study by [24] who described that small herd sizes may result in low environmental contamination. Also reported that the highly pathogenic Eimeria in cattle occurred more frequently in big farms rather than in small farms [25]. 
The strong statistically significant difference $(p<0.05)$ of the infection with Eimeria in relation to the calf housing of the farms has been demonstrated in this study. Consequently, those calves kept together showed significantly higher prevalence than calves kept at separated. This is most likely due to the fact that almost all of the study calves housed as mixed was overcrowded and in physical contact with each other that favored higher infection rate from a greater chance of licking each other and ingestion of large number of oocysts.

\section{Conclusions and Recommendations}

The study revealed that the prevalence of calf Eimeria infection in Dairy farms in the study area is $24.4 \%$ (95\% CI, 19.4-30.1). Calves in poor hygienic statuses of the farms, mixed housing of the calf and those diarrhic feces were more affected by Eimeria infection. Based on these findings the following recommendations were forwarded: Immune status of the calves could be improved by providing adequate nutrition and good hygiene as well as reducing and monitoring stress levels caused by weaning and overcrowding. Calves should be kept at separated from their dam and peers, Isolation and treatment of sick animals to prevent further disease and premise contamination.

\section{Acknowledgements}

We would like to thanks our appreciation to Haramaya University, School of Veterinary Medicine, Parasitology laboratory and personnel working in the lab for their cooperation during the study.

\section{Conflict of Interests}

The authors declare that they have no competing interests.

\section{References}

1. Ernst J, Benz GW. Intestinal coccidiosis in cattle.Clin. N. Am: Food Anim. Pract. 1986;2(2):283-291.

2. Daugschies A, Najdrowsk M. Eimeriosis in cattle: Current understanding. J Vet Med B.2005;52(10):417-427. doi:10.1111/ j.1439-0450.2005.00894.x

3. Radostits O M, Gay CC, Hinchcliff K W, Constable P D. Veterinary Medicine: A Textbook of the Diseases of Cattle, Horses, Sheep, Pigs and Goats, 10th ed. Elsevier Health Sciences, Philadelphia, PA, USA. 2007:1498-1506.

4. Bohrmann R. Toltrazuri treatment of calves in a natural outbreak of coccidiosis. Dtsch Tieraeztl Wochenschr. 1991;98:343-345.

5. Ernst J V, Ciordia H, Stuedemann J A. Coccidia in cows and calves on pasture in South Georgia (USA).Vet Parasitol. 1984;15:213-221.

6. Dedrickson B J. Coccidiosis in beef calves. Feed Lot Magazine Online. 2002;10(1).

7. Pilarczyk B, Balicka-Ramisz A, Ramisz A. Studies on coccidiosis in cattle in North-West Poland. Elec J Pol Agri Unive. 2000.3(1).

8. Lucas A S, William S S, Lindsay D S, Scaglia G, Elvinger F C, Zajac A M. The effect of weaning method on coccidial infections in beef calves. Vet Parasitol. 2007;145(3-4):228-233.
9. R M Waruiru, N C Kyvsgaard, S M Thamsborg, P Nansen, H O Bøgh, W K Munyua, et al. 2000. The prevalence and intensity of helminth and coccidial infections in dairy cattle in central KenyaVet Res Comm.2000;24(1):39-53.

10. Dawid F, Amede Y, Bekele M. Calf Coccidiosis in Selected Dairy Farms of Dire Dawa, Eastern Ethiopia. Global Veterinaria. 2012;9(4): 460464. doi:10.5829/idosi.gv.2012.9.4.64232

11. HADB. Haramaya woreda Agricultural Development Bureau. Haramaya, Ethiopia. 2009.

12. Abebe R, Kumesa B, Wessene A. Epidemiology of Eimeria infections in calves in Addis Ababa and DebreZeit Dairy Farms, Ethiopia. Intern. J. Appl. Res. Vet. Med. 2008;6(1):24-30.

13. Thrusfield M. Veterinary Epidemiology 3rd ed, Veterinary Clinical Studies, Royal (Dick) School of Veterinary Studies, University of Edinburgh, Blackwell Science Ltd, a Blackwell Publishing Company. 2007:232-246.

14. Hendrix C M. Diagnostic Veterinary Parasitology. 2nd Ed. St. Louis. Mosby Inc.1998;239-264.

15. Arslan M, Tuzer E. Prevalence of bovine Eimeriosis in Thracia, Turkey. Tr. J. Vet. And Anim. Sci. 1998;22: 161-164.

16. Kennedy M J, Kralka R A. A survey of Eimeria species in cattle in central Alberta. Can. Vet. J. 1987;28(3):124-125.

17. Rodriguez-Vivas R I, Dominguez-Alpizar J L, Torres-Acosta J F. Epidemiological factors associated to bovine coccidiosis in calves (Bosindicus) in a sub humid tropical climate. Rev. Biomed.1996;7:211-218.

18. Kassa B, Delgado A, Asegedech T. An outbreak of coccidiosis in cattle. Ethiop. Vet. Bull. 1987;3:20-27.

19. Kebadu S. A study on calf diarrhea in small- Scale dairy farms at DebreZeit.DVM thesis, Faculty of Veterinary Medicine, Addis Abeba University, DerbeZeit, Ethiopia. 1998.

20. Alemayehu A, Nuru M, Belina T. Journal of Veterinary Medicine and Animal Health. 2013;5(2):41-45,

21. Nagwa I, Toaleb K, FaragalLa M, Moghazy E, Soad E, Hassan M. Diagnosis of Eimeriosis in Cattle by ELISA Using Partially Purified Antigen.World App. Sci. J.2011;12(1):33-38.

22. Ahmed W M, Soad E. A Field Investigation on the Correlation between Reproductive Disorders and Eimeriosis in Female Buffaloes with Emphasis on Use of Partially Purified Oocyst Antigen for Diagnosis, Global Veterinaria. 2008;2(6):372-378.

23. Pandit B A. Prevalence of Coccidiosis in Cattle in Kashmir valley. Vet. Scan. 2009;4:16-20.

24. Kusiluka L J M, Kambaragea D M, Harrisonb L J S, Dabornb C J, Matthewman R W. Prevalence and seasonal patterns of coccidial infections in goats in two eco-climatic areas in Morogoro, Tanzania. Small Rumin Res. 1998;30(2):85-91.

25. Klockiewicz M J, Kaba K, Tomczuk E, Janecka A B, Sadzikowski K, Rypuła M, et al. The epidemiology of calf coccidiosis (Eimeriaspp) in Poland.Parasitol Res. 2007;101: 121-128. 